\title{
I'll be Good for Grandma: Institutional and Relational Trust and COVID-19 Restriction Compliance
}

\author{
Derly M Andrade-Molina \\ Universidad de Especialidades Espíritu Santo: Universidad de Especialidades Espiritu Santo \\ Juan Carlos Fernandez-Cadena \\ Universidad de Especialidades Espíritu Santo: Universidad de Especialidades Espiritu Santo \\ Mario A Fernandez \\ Auckland Council \\ Lauren A Rhodes \\ Escuela Superior Politecnica del Litoral \\ Gonzalo E Sanchez ( $\sim$ edsanche@espol.edu.ec) \\ Escuela Superior Politécnica del Litoral https://orcid.org/0000-0003-2523-5407
}

Research

Keywords: COVID, trust, relational trust, institutional trust, compliance.

Posted Date: November 2nd, 2021

DOI: https://doi.org/10.21203/rs.3.rs-929565/v1

License: @) (1) This work is licensed under a Creative Commons Attribution 4.0 International License. Read Full License 


\section{Abstract}

behavior with health campaigns. We examine Guayaquil, Ecuador which was hit particularly hard in the first few months of the pandemic. As lockdowns and social distancing led families to rely on others to secure food or medical assistance, perceptions on trust and the dynamics of social capital during the initial (and worst) months of the pandemic were particularly important.

Methods: This paper uses a unique dataset of people receiving a COVID test after suspicion of infection. People in our dataset were active during the height of the pandemic and faced the possibility of needing to rely on others in the case of testing positive. We use regression analysis to study the relation between compliance with mobility restrictions and institutional and relational trust.

Results: We find that trusting that close relations (such as family) will be there for you in the case of falling ill is associated with a significant increase in the probability of complying with health campaigns. Additionally, we find that trust in the government has a weak relationship to compliance. However, compliance decreases when examining increased trust in the police but increases with trust in the military.

Conclusions: The findings show that enhancing trust may improve compliance with social distancing measures. However, increasing trust in specific groups could have negative consequences. Importantly, compliance could be increased by emphasizing in campaigns that your behavior could influence the health of those who you care about.

\section{Background}

Trust is a fundamental component of social capital, and as such, a great deal of research has been devoted to the importance of trust and social capital in strengthening financial institutions and its role in economic growth [1-7]. Social capital, sometimes referred to as civic capital, is defined generally as "those persistent and shared beliefs and values that help a group overcome the free rider problem in the pursuit of socially valuable activities" [8]. While this definition certainly encompasses economic activities, trust as a part of social capital is woven even deeper into the thread of the economy and the overall society. Trust can help to keep us safe.

In the wake of the COVID-19 pandemic which has wreaked havoc in various aspects across the globe, trust has been a heavily discussed theme. We adopt the general definition of trust put forward in Romero [9] which states that trust is the "willingness to be vulnerable to another person, group, or organization based on the perception that the trusted party is benevolent, competent, and behaves with integrity." Several studies have found a positive relationship between trust and prosocial behavior (or at least rule compliance) indicating that trust is a valuable component in successful health campaigns [9-11]. Due to the need for governments to control the spread of the virus, a series of campaigns have been implemented to encourage social distancing as well as other health measures [12]. The effectiveness of many of these campaigns are dependent on the trust that the respective societies have in the related institutions. Studies in Europe $[13,14]$ as well as the United States $[15,16]$ have shown an increased adherence to mobility restrictions in areas with higher levels of pre-pandemic trust.

Given that many of the campaigns to prevent the spread of COVID have relied on mandates that can be considered costly to the majority of people (such as social distancing and lockdowns, for example), the willingness of people to comply with the measures relies at least partially on that citizens trust that the government and related scientific community are giving sound information with accurate policies to address the situation [17]. It has been previously noted that trust plays a vital role in the dissemination of health campaigns as people are more willing to believe and act upon the information when it is received from a well trusted institution, particularly one with community ties $[18,19]$. Within several communities throughout the world, a lack of trust in these key institutions left divided nations and a rapid increase in the spread of the virus as people failed to believe the scientific community and/or the government was responding accurately. Additionally, trust is needed in enforcing institutions in order for people to feel safe enough to continue to conduct their businesses.

An aspect of trust that has been less examined in the context of COVID is how relational trust (trust in family, friends, neighbors, etc.) can affect behavior. We add to the literature by examining how relational trust along with institutional trust influences compliance behavior. Relational trust is characterized by being based on previous behavior and a shared identity [20]. While trust is often used as a broad term, previous studies have found that trust in political institutions is statistically unrelated to relational trust [21]. However, relational trust has been shown to promote positive and prosocial behavior in the settings of professional learning for school principals [22] and can lead to lower mortality rates where there is a high level of relational trust within a community as seen within Chicago neighborhoods [23].

The city of Guayaquil, Ecuador's largest city, was hit particularly hard in the first few months of the COVID pandemic. The unprecedented magnitude of the health crisis alongside the lack of infrastructure and the slow response from central and local governments, resulted by the end of April 2020 in at least 9 thousand COVID-related deaths nationally, from which it is estimated that $40 \%$ corresponds to Guayaquil. The country's strategy to fight the virus entailed lockdown measures during which only essential services (e.g. grocery stores, pharmacies, clinics, and gas stations) could remain open. Travel was limited, gatherings were cancelled, and public venues closed. Due to the considerable size of the population relying on day-to-day informal business, the lockdown slowed down the progression of the pandemic but did not achieve a total elimination target. Nonetheless, movement restrictions and social distancing led families to rely on others (e.g. family, friends, acquaintances, central and local governments) to secure food or medical assistance. These may have redefined perceptions on trust and, consequently, the dynamics of social capital during the initial (and worst) months of the pandemic.

In this sense, another contribution of this paper is the use of a unique dataset of people in Guayaquil in the process of receiving a COVID test after suspicion of infection. This unique dataset is particularly useful in evaluating trust in the COVID context because the people in our dataset were, at least to some degree, active during the height of the pandemic and were facing the real possibility of needing to rely on others in the case of testing positive. 


\section{Methods \\ Sample and Survey}

We constructed a questionnaire in which respondents were asked about how much they trust their families, friends, work colleagues, neighbors, and other acquaintances will take care of them if they get sick with COVID (relational trust). Respondents were also asked about their trust in the role that institutions (e.g. government, national and local media, police and army forces) have on the control of the pandemic (institutional trust). Compliance with lockdown orders is found from a question about the number of days since the last time the respondent participated in a gathering with more than 10 people. All responses related to trust were measured on Lickert scales where 1 represents the lowest level of trust and 10 the highest.

The questionnaire (paper and tablet-based) was administered between April and July 2020 to a sample of patients arriving to the COVID testing facilities of Universidad Espiritu Santo in Guayaquil. After signing the informed consent, respondents were interviewed and informed about the purpose of the study and information confidentiality. After the completion of the questionnaire, it was linked to an anonymous identifier that was used later to match with the results of the COVID test.

Table 1 reports the descriptive statistics of the variables used for the analysis. Initially, 2715 individuals requested a COVID test though not all accepted to participate in the questionnaire or had records that could be linked to the test results. We conduct the analysis on 1182 respondents for which the questionnaire could be administered and 1053 respondents for which the questionnaire could be linked to the test results.

For our analysis, "Comply" is a binary variable taking a value of 1 if the respondent indicated that they had not attended a gathering of 10 or more people within the last three weeks at the time of the questionnaire. Approximately $82.5 \%$ of the respondents indicated compliance by our definition.

The trust questions and corresponding variables can be categorized into two groups. The first group asks the respondents to indicate on a scale from 1 to 10 their level of trust that the group in question (family, friends, coworkers, neighbors, or others) will take care of them should they fall ill with COVID. From this, we formed binary trust variables, "High Trust in X", which take on a value of 1 if the respondent indicated a trust level from 6 to 10 , and a 0 otherwise where X is one of the aforementioned groups. Not surprisingly, "High Trust in Family" had the highest proportion of participants indicating a high level of trust with $92.45 \%$ of respondents marking a level between 6 and 10 . In contrast, only $19 \%$ of the respondents indicated having high trust in others (not family, friends, coworkers, or neighbors).

The second group of trust questions asks the respondents to indicate their level of trust on a scale from 1 to 10 that the entity in question (the government, Ecuadorian national media, international media, police, and military) will respond appropriately in addressing the pandemic. Again, from this information we formed binary variables, "High Trust in Y", that have a value of 1 if the respondent marked a level of trust between 6 and 10 where $Y$ is one of the aforementioned entities. Approximately $41.6 \%$ indicated having a high level of this trust in this regard in the government, $51 \%$ in the national media, $80.2 \%$ in the international media, $64.5 \%$ in the police, and $70.1 \%$ in the military.

Finally, we have demographic and COVID test variables for each respondent. 53\% of the respondents were female with an overall average age of 39.9 . After the survey, it was concluded that $63.8 \%$ of the respondents received positive COVID- 19 test results, $20.5 \%$ received negative results, and $15.7 \%$ of the results could not be determined as being either positive or negative.

Figure 1 shows the probability of compliance by the level of trust (low or high) that different groups of people will take care of the respondent. The figure shows that trust in family and friends is positively related to higher compliance. That is, stronger ties with family and friends predict not attending or participating on gatherings with more than 10 persons. The figure does not show important differences for coworkers, neighbors and others. 
Table 1

Descriptive Statistics

\begin{tabular}{|lccccc|}
\hline Variable & Obs & Mean & Std. Dev. & Min & Max \\
\hline Comply & 1182 & .825 & .38 & 0 & 1 \\
\hline High Trust in Family & 1182 & .924 & .265 & 0 & 1 \\
\hline High Trust in Friends & 1182 & .726 & .446 & 0 & 1 \\
\hline High Trust in Coworkers & 1182 & .607 & .489 & 0 & 1 \\
\hline High Trust in Neighbors & 1182 & .381 & .486 & 0 & 1 \\
\hline High Trust in Others & 1182 & .19 & .393 & 0 & 1 \\
\hline High Trust in Government & 1182 & .416 & .493 & 0 & 1 \\
\hline High Trust in National Media & 1182 & .51 & .5 & 0 & 1 \\
\hline High Trust in International Media & 1182 & .802 & .399 & 0 & 1 \\
\hline High Trust in the Police & 1182 & .645 & .479 & 0 & 1 \\
\hline High Trust in the Military & 1182 & .701 & .458 & 0 & 1 \\
\hline Female & 1050 & .531 & .499 & 0 & 1 \\
\hline Age & 1039 & 39.882 & 15.928 & 0 & 90.528 \\
\hline Positive for Covid-19 & 1053 & .638 & .481 & 0 & 1 \\
\hline Negative for Covid-19 & 1053 & .205 & .404 & 0 & 1 \\
\hline Indetermined result for Covid-19 & 1053 & .157 & .364 & 0 & 1 \\
\hline
\end{tabular}

In Figure 2 we focus on trust in different institutions for controlling the pandemic and compliance behavior. It has the same features as Figure 1 and shows little evidence of differences in compliance by level of trust, with the exception of the military for which higher trust is associated with higher compliance.

\section{Statistical Analysis}

The graphical analysis provides a first idea of the differences in compliance as a function of trust. However, it does not allow statistical inference. To assess the degree to which trust in institutions and relational connections predicts the likelihood of complying with the COVID-19 restrictions, we use a linear probability model (LPM) as our base specification:

Comply $_{i}=\beta_{0}+\beta_{1}$ Family $_{i}+\beta_{2}$ Friends $_{i}+\beta_{3}$ Coworkers $_{i}+\beta_{4}$ Neighbors $_{i}+\beta_{5}$ Others $_{i}+\beta_{6}$ Government $_{i}+\beta_{7}$ NationalMedia $_{i}+\beta_{8}$ Internatior

1

Comply $_{i}$, is a binary variable that takes a value of 1 if the respondent did not attend any face-to-face meetings or reunions with 10 or more people within the last 3 weeks, and a 0 otherwise. For each group or institution included in expression 1, we included a binary variable representing high trust as described in the previous section. The estimated coefficients for these variables are the Ordinary Least Squares (OLS) estimates of the differences in predicted compliance between high and low trust in the respective group or institution. Further, a second specification expands Equation 1 to control for respondents' age and gender, and the result of the COVID test, either positive or negative. Note that some respondents received indeterminant COVID-19 test results. Then this variable is excluded to avoid perfect multicollinearity. In addition, results are checked for robustness by re-estimating the same specifications through Logit and Probit. We report marginal effects of the variables evaluated at their mean values. The reported p-values are robust to heterogeneity.

\section{Results}

Results for the four specifications can be found in Table 2. We find that across specifications trusting family indicates a significantly higher likelihood of compliance where compliance is defined as not meeting or gathering in groups of 10 or more. This difference is approximately 13 percentage points and is significant at the $1 \%$ level in all the specifications. A smaller difference of approximately 6 percentage points is seen for friends.

In contrast, believing that one's neighbors will be willing to care for them in the case of contracting covid implies a significant decrease in the likelihood of compliance across all specification of around 7 percentage points. A similar, but smaller and less significant result is found for coworkers. This opposite result from what is observed with family and friends could potentially indicate that it is the care for the wellbeing of those relationally close to you that drives compliance. There is no evidence a difference in compliance by trust in others.

The results corresponding to institutional trust are dependent upon the institution in question. Trusting that the government will manage the COVID-19 pandemic appropriately is associated with a small positive change in compliance of approximately 4 percentage points with different levels of significance. A bigger and highly significant difference of approximately 13 percentage points correspond to the military. However, trusting that the police will effectively address the pandemic has a significant negative relationship with compliance of approximately 10 percentage points. There is no evidence of a difference in compliance as a function of trust in national or international media, demographics, or the test results. These results indicate that policies purely aimed at increasing trust in institutions as a means of nudging compliance may not always have the desired results.

Loading [MathJax]/jax/output/CommonHTML/fonts/TeX/fontdata.js

Page $4 / 8$ 
Table 2. Regression estimates of reported compliance on high level of trust in different groups

\begin{tabular}{|c|c|c|c|c|}
\hline & $\begin{array}{l}(1) \\
\text { LPM }\end{array}$ & $\begin{array}{l}(2) \\
\text { LPM }\end{array}$ & $\begin{array}{c}(3) \\
\text { Logit }\end{array}$ & $\begin{array}{c}(4) \\
\text { Probit } \\
\end{array}$ \\
\hline Family & $\begin{array}{l}0.166 * * * \\
(0.00218)\end{array}$ & $\begin{array}{l}0.132^{* *} \\
(0.0169)\end{array}$ & $\begin{array}{l}0.128 * * * \\
(0.00312)\end{array}$ & $\begin{array}{l}0.121 * * * \\
(0.00481)\end{array}$ \\
\hline Friends & $\begin{array}{c}0.0766^{* *} \\
(0.0176)\end{array}$ & $\begin{array}{l}0.0546^{*} \\
(0.0907)\end{array}$ & $\begin{array}{l}0.0533 \\
(0.101)\end{array}$ & $\begin{array}{l}0.0541^{*} \\
(0.0989)\end{array}$ \\
\hline Coworkers & $\begin{array}{r}-0.0128 \\
(0.644)\end{array}$ & $\begin{array}{c}-0.0555^{*} \\
(0.0565)\end{array}$ & $\begin{array}{c}-0.0600 * \\
(0.0524)\end{array}$ & $\begin{array}{c}-0.0579 * \\
(0.0681)\end{array}$ \\
\hline Neighbors & $\begin{array}{c}-0.0924 * * * \\
(0.00105)\end{array}$ & $\begin{array}{c}-0.0700 * * \\
(0.0235)\end{array}$ & $\begin{array}{c}-0.0755^{* *} \\
(0.0100)\end{array}$ & $\begin{array}{c}-0.0710 * * \\
(0.0167)\end{array}$ \\
\hline Others & $\begin{array}{l}0.0420 \\
(0.188)\end{array}$ & $\begin{array}{l}0.0203 \\
(0.573)\end{array}$ & $\begin{array}{l}0.0214 \\
(0.529)\end{array}$ & $\begin{array}{l}0.0188 \\
(0.590)\end{array}$ \\
\hline Government & $\begin{array}{l}0.0351 \\
(0.171)\end{array}$ & $\begin{array}{l}0.0476^{*} \\
(0.0802)\end{array}$ & $\begin{array}{c}0.0556^{* *} \\
(0.0474)\end{array}$ & $\begin{array}{l}0.0489^{*} \\
(0.0795)\end{array}$ \\
\hline National Media & $\begin{array}{r}-0.0149 \\
(0.595)\end{array}$ & $\begin{array}{l}0.0351 \\
(0.281)\end{array}$ & $\begin{array}{l}0.0279 \\
(0.368)\end{array}$ & $\begin{array}{l}0.0312 \\
(0.316)\end{array}$ \\
\hline International Media & $\begin{array}{r}-0.0156 \\
(0.630)\end{array}$ & $\begin{array}{c}-0.0391 \\
(0.261)\end{array}$ & $\begin{array}{r}-0.0356 \\
(0.291)\end{array}$ & $\begin{array}{r}-0.0383 \\
(0.272)\end{array}$ \\
\hline Police & $\begin{array}{l}-0.104^{* * * *} \\
(0.000000)\end{array}$ & $\begin{array}{c}-0.0960 * * * \\
(0.000319)\end{array}$ & $\begin{array}{c}-0.110^{* * * *} \\
(0.000441)\end{array}$ & $\begin{array}{c}-0.0944 * * * \\
(0.00161)\end{array}$ \\
\hline Military & $\begin{array}{c}0.129 * * * \\
(0.000000)\end{array}$ & $\begin{array}{c}0.131 * * * \\
(0.000000)\end{array}$ & $\begin{array}{c}0.146 * * * \\
(0.000000)\end{array}$ & $\begin{array}{c}0.129 * * * \\
(0.000000)\end{array}$ \\
\hline Age & & $\begin{array}{c}0.000977 \\
(0.197)\end{array}$ & $\begin{array}{c}0.00103 \\
(0.167)\end{array}$ & $\begin{array}{c}0.00101 \\
(0.190)\end{array}$ \\
\hline Positive for Covid-19 & & $\begin{array}{r}-0.0249 \\
(0.445)\end{array}$ & $\begin{array}{r}-0.0183 \\
(0.574)\end{array}$ & $\begin{array}{r}-0.0227 \\
(0.508)\end{array}$ \\
\hline Negative for Covid-19 & & $\begin{array}{l}0.0164 \\
(0.658)\end{array}$ & $\begin{array}{l}0.0278 \\
(0.485)\end{array}$ & $\begin{array}{l}0.0250 \\
(0.553)\end{array}$ \\
\hline Female & & $\begin{array}{l}0.0209 \\
(0.383)\end{array}$ & $\begin{array}{l}0.0260 \\
(0.256)\end{array}$ & $\begin{array}{l}0.0234 \\
(0.319)\end{array}$ \\
\hline Constant & $\begin{array}{c}0.633^{* * *} \\
(0.000000)\end{array}$ & $\begin{array}{c}0.650 * * * \\
(0.000000)\end{array}$ & & \\
\hline Observations & 1,182 & 1,023 & 1,023 & 1,023 \\
\hline
\end{tabular}

Each column represents an specification. LPM: Linear Probability Model. The dependent variable is binary and indicates reported compliance with social distance. See text for details. Robust pvalues in parentheses.

${ }^{* * *} p<0.01,{ }^{* *} p<0.05,{ }^{*} p<0.1$

\section{Discussion}

Trust has been an important theme when examining campaigns aimed at preventing the spread of COVID-19. We study trust in Guayaquil, Ecuador which was hit particularly hard early on in the pandemic. We examine the influence of trust on compliance of social distancing measures using a unique dataset of people in Guayaquil who were in the process of testing for COVID. Sampling from this group was beneficial as the respondents were looking at the pressing possibility of needing to rely on others in the case of a positive test result.

We find that stronger familial ties as seen through stronger relational trust in family indicators is related to higher compliance in social distancing measures. This is likely due to the desire to protect those who you care about. A similar result is seen for friends, but a decrease in compliance is seen for increased trust in neighbors and coworkers. Additionally, we find that trust in the government has a weaker relationship with compliance, but trust that the police will adequately address the pandemic is associated with decreased compliance, while trust in the military is associated with increased compliance. These results show that a universal enhancement of trust will not necessarily benefit public health, but rather trust should be examined carefully in campaign design.

\section{Limitations}

Our study utilizes self-reported data from a sample of people being tested for COVID in Guayaquil, Ecuador. We study a highly relevant group of people when looking at policies aimed at public health: those who were likely active during the height of the pandemic crisis. The findings in this study are particularly relevant to this subset of the population, but potentially the influence of trust on behavior might be different for other groups. For instance, those who were not active outside of the home during the pandemic. However, those who were not active outside of the home were by definition following the health campaigns and therefore are not as great of a concern when looking at policies to increase social distancing compliance.

Additionally, self-reported data on compliance with the social distancing mandates may be overstated (that is, people may not have complied as much as they said that they complied). However, this potential issue is likely unrelate to the other variables and therefore would not influence our results.

\section{Conclusions}

When designing campaigns to increase compliance with public health policies such as social distancing mandates as seen with the COVID-19 pandemic, it is important that policy makers consider how trust in various groups may be influenced. We study the relationship between trust and compliance with social Loading [MathJax]/jax/output/CommonHTML/fonts/TeX/fontdata.js 
distancing mandates in Guayaquil, Ecuador during the COVID-19 pandemic. Our results demonstrate that enhancing trust can improve compliance in social distancing measures but enhancing trust in certain groups could have undesirable consequences. Furthermore, compliance could be increased by emphasizing in campaigns that your behavior could influence the health of those who you care about.

\section{Abbreviations}

LPM

linear probability model

OLS

Ordinary Least Squares.

\section{Declarations}

Ethics approval and consent to participate. This study was approved by the Expedited Ethics Committee of the Ecuadorian Health Ministry (MSP-024-2020). All the participants signed an informed consent.

Consent for publication. Not applicable.

Availability of data and materials. The data analyzed during the current study are not publicly available due to privacy reasons but are available from the corresponding author on reasonable request.

Code availability. Stata Do files are fully available from the corresponding author.

Competing interests. None.

Funding. This work was supported by Centro de Investigaciones Universidad Espíritu Santo and Fideicomiso Sumar Juntos. The sponsors had no role in the collection, analysis, and interpretation of data; in the writing of the report; nor in the decision to submit the article for publication.

Authors' contributions. DA, contributed to the management of the study; was responsible for data collection, and the research design. JF, contributed to the management of the study; was responsible for data collection, and the research design. MF, contributed to the research design, analysis and interpretation of the data and revisions of the manuscript. LR, contributed to the research design, analysis and interpretation of the data and drafted the manuscript. GS, contributed to the research design, statistical analysis, and revisions of the manuscript. All authors reviewed and approved the final manuscript.

Acknowledgements. We thank Katheryn Sacheri Viteri y Rubén Armas Gonzalez for their outstanding assistance in the data collection.

\section{References}

1. Knack S, Keefer P. Does social capital have an economic payoff? A cross-country investigation. Q J Econ. 1997;112(4):1251-88.

2. Zak PJ, Knack S. Trust and growth. Econ J (London). 2001;111(470):295-321.

3. Beugelsdijk S. Trust and economic growth: a robustness analysis. Oxf Econ Pap. 2004;56(1):118-34.

4. Akçomak is, ter Weel B. Social capital, innovation, and growth: Evidence from Europe. Eur Econ Rev. 2009;53(5):544-67.

5. Dincer OC, Uslaner EM. Trust and growth. Public Choice. 2010;142(1-2):59-67.

6. Algan Y, Cahuc P. Trust, growth, and well-being: New evidence and policy implications. Handb Econ Growth. 2014; 2: 49-120.

7. Bottazzi L, Da Rin M, Hellmann T. The importance of trust for investment: Evidence from venture capital. Rev Financ Stud. 2016;29(9):2283-318.

8. Guiso L, Sapienza P, Zingales L. Civic capital as the missing link. In: Handbook of Social Economics. Elsevier; 2011. p. 417-80.

9. Romero LS. Trust, behavior, and high school outcomes. J Educ Adm. 2015;53(2):215-36.

10. Dirks KT, Ferrin DL. The role of trust in organizational settings. Organ sci. 2001;12(4):450-67.

11. Colquitt JA, Scott BA, LePine JA. Trust, trustworthiness, and trust propensity: a meta-analytic test of their unique relationships with risk taking and job performance. J Appl Psychol. 2007;92(4):909-27.

12. Bonell C, Michie S, Reicher S, West R, Bear L, Yardley L, et al. Harnessing behavioural science in public health campaigns to maintain "social distancing" in response to the COVID-19 pandemic: key principles. J Epidemiol Community Health. 2020;74(8):617-9.

13. Bargain O, Aminjonov U. Trust and compliance to public health policies in times of COVID-19. J Public Econ. 2020;192(104316):104316.

14. Bartscher AK, Seitz S, Siegloch S, Slotwinski M, Wehrhöfer N. Social capital, and the spread of covid-19: Insights from European countries. SSRN Electron J [Internet]. 2020; Available from: http://dx.doi.org/10.2139/ssrn.3616714

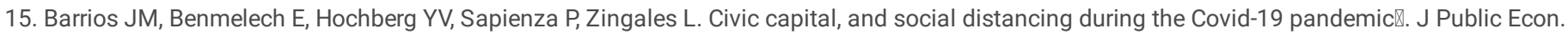
2021;193(104310):104310.

16. Borgonovi F, Andrieu E. Bowling together by bowling alone: Social capital and COVID-19. Soc Sci Med. 2020;265(113501):113501.

17. Van Bavel JJ, Baicker K, Boggio PS, Capraro V, Cichocka A, Cikara M, et al. Using social and behavioural science to support COVID-19 pandemic response. Nat Hum Behav. 2020;4(5):460-71. 
18. Putnam RD. Bowling alone: The collapse and revival of American community. In: Proceedings of the 2000 ACM conference on Computer supported cooperative work - CSCW '00. New York, New York, USA: ACM Press; 2000.

19. Stephens KK, Rimal RN, Flora JA. Expanding the reach of health campaigns: community organizations as meta-channels for the dissemination of health information. J Health Commun. 2004;9 Suppl 1(sup1):97-111.

20. Poppo L, Zhou KZ, Li JJ. When can you trust "trust"? Calculative trust, relational trust, and supplier performance: Trust and Supplier Performance. Strategic Manage J. 2016;37(4):724-41.

21. Robbins BG. From the general to the specific: How social trust motivates relational trust. Soc Sci Res. 2016; 55:16-30.

22. Cranston J. Relational trust: The glue that binds a professional learning community. Alta J Educ Res. 2011;57(1):59-72.

23. Lochner KA, Kawachi I, Brennan RT, Buka SL. Social capital and neighborhood mortality rates in Chicago. Soc Sci Med. 2003;56(8):1797-805.

24. Pagliaro S, Sacchi S, Pacilli MG, Brambilla M, Lionetti F, Bettache K, et al. Trust predicts COVID-19 prescribed and discretionary behavioral intentions in 23 countries. PLoS One. 2021;16(3): e0248334.

\section{Figures}
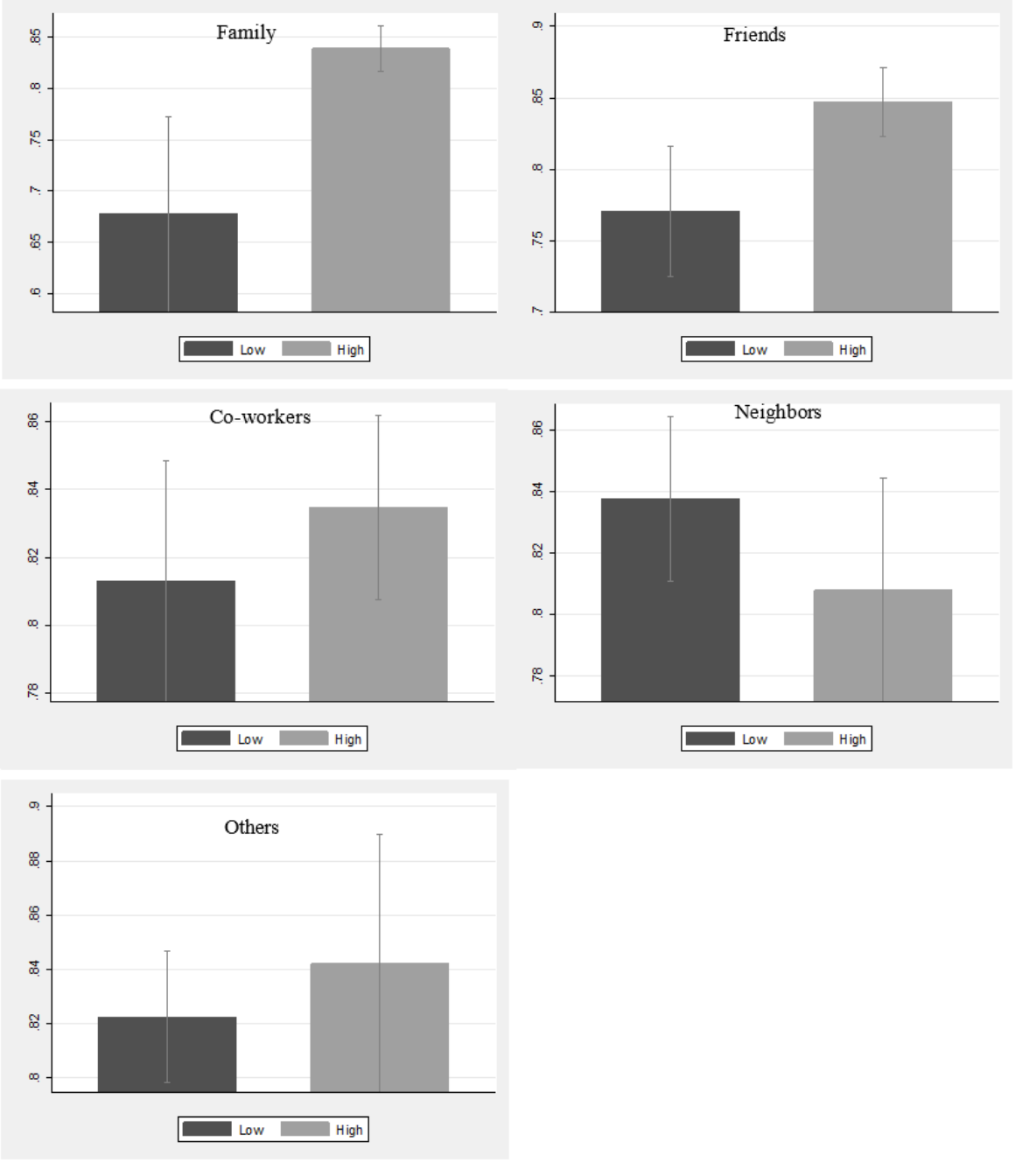

Figure 1

Probability of compliance by the level of trust - relational trust 

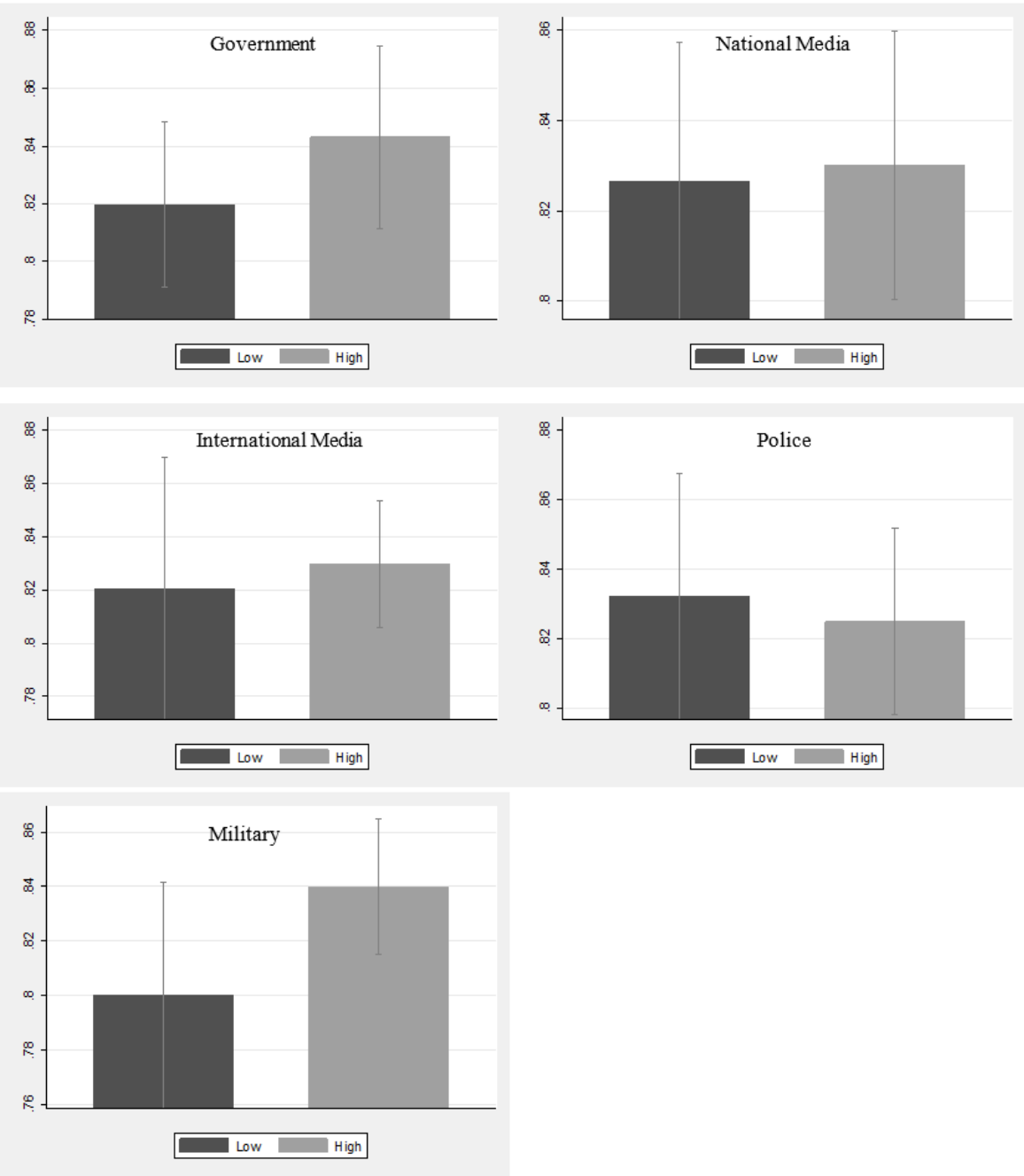

Figure 2

Probability of compliance by the level of trust - institutional trust 